\title{
DEVELOPMENT OF A NON-DESTRUCTIVE METHOD FOR DETERMINATION OF PH OF PAPER ARTIFACTS USING DIFFUSE REFLECTANCE SPECTROSCOPY AND REGRESSION ANALYSIS
}

\author{
BOGDAN M. BOȘCA ${ }^{\mathrm{a}}$, AUGUSTIN C. MOȚa,
}

\begin{abstract}
One of the most important factors that influence the quality and resistance to chemical and microorganism degradation of paper, historical artifacts and art works is $\mathrm{pH}$. Despite the simplicity of electrochemical devices that are mostly used nowadays for $\mathrm{pH}$ determination, some of them have limitations in terms of precision and time response. In this study, a rapid, simple, and highly precise method for determination of $\mathrm{pH}$ of paper was developed using non-destructive reflectance spectroscopy and commercial non-bleeding $\mathrm{pH}$ indicator test strips. The calibration curve was constructed using standard Britton-Robinson buffers and was done in the $4.00-9.50 \mathrm{pH}$ range. Using univariate regression analysis, the largest linearity domain $\left(R^{2}=0.9992, p<0.000\right)$ was found to be at $590 \mathrm{~nm}$ wavelength, as established from the loadings plot for a PCA analysis. The proposed method, alongside other two known methods, were applied on three real samples, including a 1710 Greek New Testament. No statistical significance ( $p>0.05$, ANOVA) was observed between the three methods, supporting the accuracy of the proposed method. Fischer test reveals a strongly significant higher precision for the tested method $(\mathrm{p}<0.01)$. The values of the determined $\mathrm{pH}$ for the three real samples were $8.47 \pm 0.03,7.78 \pm 0.07$ and $7.99 \pm 0.08$.
\end{abstract}

Keywords: non-destructive method, pH determination, reflectance spectroscopy

\section{INTRODUCTION}

Paper represents one of the most used cultural and historical data carrier. [1, 2] It was discovered by the Egyptians in $3000 \mathrm{BC}$ and the papermaking process was developed and improved in China in $105 \mathrm{CE}$. Over

a Chemometrics and Bioanalytical Chemistry Laboratory, Analytica Research Center, Department of Chemistry, Faculty of Chemistry and Chemical Engineering, Babeș-Bolyai University, 11 Arany János Street, RO-400028 Cluj-Napoca, Romania

*Corresponding author: augustin.mot@ubbcluj.ro 
the years, scientific, religious, political manuscripts and drawings have been written or drawn on paper such as the Bible, Egyptian hieroglyphs, and others. Preservation of such valuable paper artifacts is a very important aspect in order to improve the communication between generations. [1,3] Among many natural factors-temperature, humidity, light, presence of microorganisms, oxidative agents-which influence paper degradation in time, $\mathrm{pH}$ is one of the most important ones. [1, 2] Moreover, composition of the paper is a determinant factor in the degradation process. The main composite is represented by cellulose fibres. [4] Kaolin, clay, calcium carbonate, lignin represent auxiliary materials which are generally added to improve some physical characteristics of paper such as opacity, mechanic resistance and thickness, to name few. [5, 6] The ratio between these materials depends on the final use of paper, like writing, printing, decoration and others. [5, 7]

Validated analytical methods have been developed for monitoring the relevant parameters of paper-opacity, humidity, $\mathrm{pH}$, thickness —and to discover the optimal conditions for keeping important documents or drawings, in order to avoid or reduce their deterioration in time. [3] As the presence of free radicals-usually detected by electron paramagnetic resonance spectroscopy $[8,9]$ - or the opacity-frequently studied by diffuse reflectance UV-Vis spectroscopy [7] —help us to find the age of the paper, $\mathrm{pH}$ values provide useful information regarding the deterioration process. There are already some known analytical tools used in order to obtain information regarding the $\mathrm{pH}$ of paper, [4] such as volatile organic compounds determination and flat surface $\mathrm{pH}$ electrode. $[2,10,11]$ Also, the methods used have to be non-destructive, due to the fact that most of the analyzed papers are of historical importance and some of them are unique, especially old drawings.

The mechanism of the deterioration processes is greatly influenced by $\mathrm{pH}$. An acidic medium produces the degradation of cellulose through acidcatalyzed hydrolysis, whereas autooxidation appears in a more alkaline medium as a degradation path. $[4,10]$ The deterioration process is faster when $\mathrm{pH}$ shows a low value and this is why, in general, the paper produced between 1850 and 1900-that has acidic $\mathrm{pH}$-is more susceptible to degradation than the paper produced before 1850-that has alkaline $\mathrm{pH}$. [10]

The aim of this work was to develop a non-destructive method for the determination of the $\mathrm{pH}$ of paper artifacts based on diffuse reflectance spectroscopy which is faster and more precise than the classical electrodebased methods. The diffuse reflectance spectra were depending upon the color of the $\mathrm{pH}$ indicator strips caused by the change in the $\mathrm{pH}$ of the ultrapure water transmitted through the tested paper sample in contact with the $\mathrm{pH}$ indicator strips, thus eliminating the acid and alkaline errors typical for electrode-based methods and increasing the number of the calibration points as compared to the classical methods. 


\section{RESULTS AND DISCUSSION}

The diffuse reflectance spectra of the three-bands non-bleeding $\mathrm{pH}$ indicator test strips (band 2 - orange-green and band 3 - yellow-violet) corresponding for all tested $\mathrm{pH}$ standard solutions, in the range $4.00-9.50$ are presented in Figure 1A, alongside the image of the tested strips (Figure 1B). Band 1 - violet-red was not used due to the limited spectral information as revealed by preliminary results carried out on each single band experiments and due to the fact that the reading window of the integrating sphere was limited in size $(1 \times 1 \mathrm{~cm})$ and allowed maximum two bands at a time.

A.

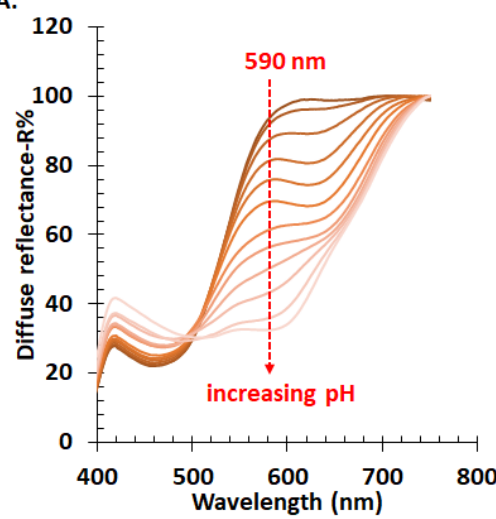

c.

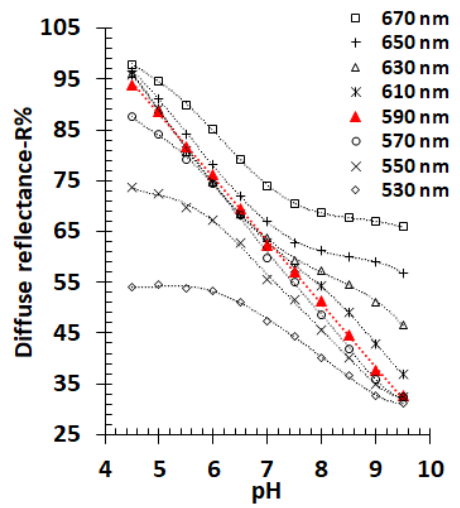

B.

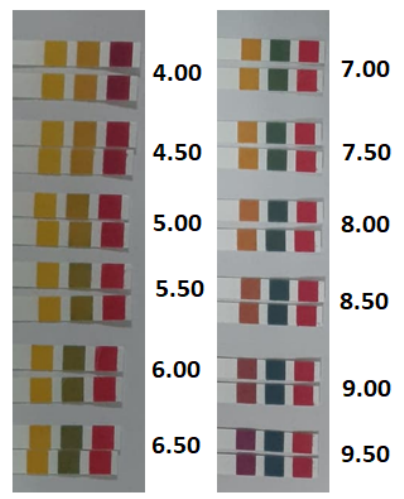

D.

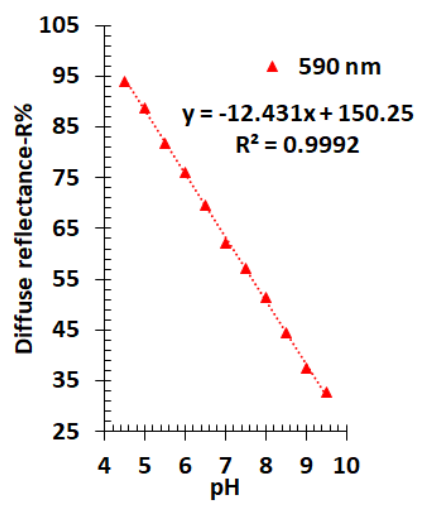

Figure 1. A. Reflectance spectra profile-after min-max normalization-of the nonbleeding $\mathrm{pH}$ indicator test strips for $\mathrm{pH}$ standard solutions in the range $4.00-9.50$. Position of $590 \mathrm{~nm}$ wavelength is indicated by an arrow, as the $\mathrm{pH}$ increases. B. Image of the non-bleeding $\mathrm{pH}$ indicator test strips used for calibration test, in duplicate, for each tested $\mathrm{pH}$ value. C. Variation of the calibration curves and their linearity deviation, at various wavelengths. D. Selected calibration curve at the optimum wavelength $(590 \mathrm{~nm})$. 
As the $\mathrm{pH}$ increases, a clear gradually decrease in reflectance is observed in the $500-700 \mathrm{~nm}$ range, with a maximum gradient around $600 \mathrm{~nm}$, as expected by the color of the bands from the tested strips. A minor gradual increase in the $400-500 \mathrm{~nm}$ range is also observed. In order to construct an optimum calibration curve, univariate regression models were used at various wavelengths. A plot that indicates the variation of the calibration curves at the most important wavelengths is indicated in Figure 1C. Above $600 \mathrm{~nm}$, the calibration curves exhibit a deviation from linearity at alkaline $\mathrm{pH}$ values, that gradually enhances as the wavelength increases. A similar behavior was observed at wavelengths lower than $580 \mathrm{~nm}$, but the deviation from linearity is at acidic $\mathrm{pH}$. The coefficient of determination, as well as the bivariate scatterplots were used to assess the linearity and its domain. Following this analysis, the optimum wavelength came out to be $590 \mathrm{~nm}$, as shown in Figure 1D.

Another approach that was used for the determination of the optimum wavelength was the inspection of the loading plot (or correlation circle) obtained after application of PCA on the entire data matrix. The loadings profile indicates two regions of maximum spread of the variation on the first component that takes more than $83 \%$ of the information, around $414 \mathrm{~nm}$ and $590 \mathrm{~nm}$, as indicated in Figure 2.
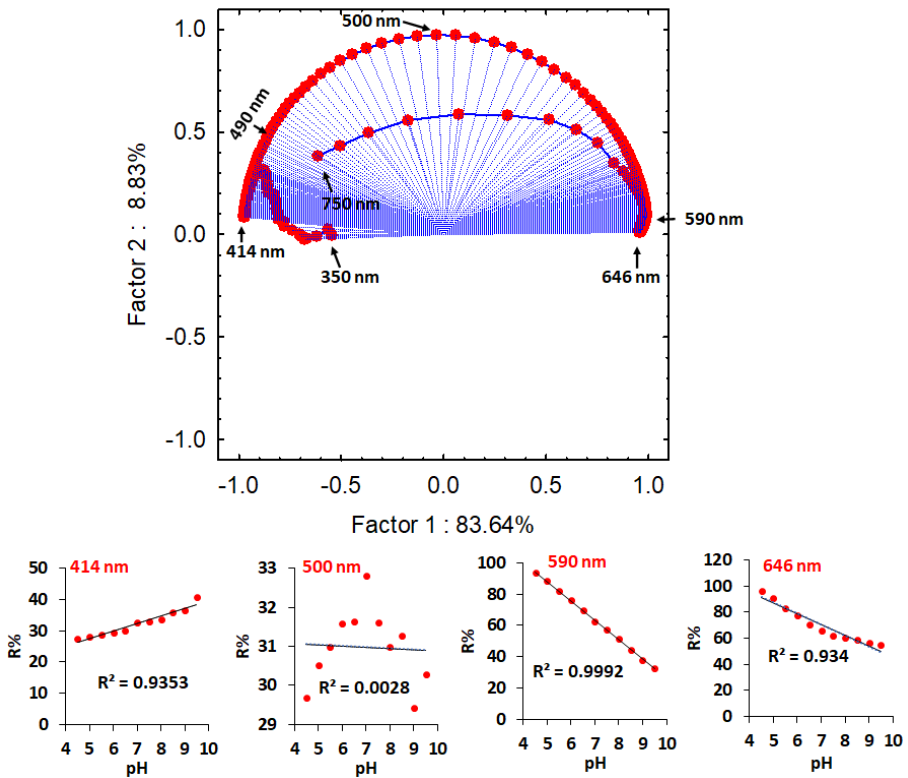

Figure 2. Loadings profile for all the variables (i.e. min-max normalized reflectance values) in the 350 - $750 \mathrm{~nm}$ spectral domain, at an interval of $1 \mathrm{~nm}$-after application of PCA analysis. Some wavelength points are indicated by arrows, the others are removed for clarity. Univariate calibration curves for some of the indicated wavelengths are presented alongside their corresponding determination coefficient. 
A minimum variation is expected around the $500 \mathrm{~nm}$ wavelength based on Figure 2. This profile is justified and explained by the original variable profile form Figure 1A. Despite a positive and significant correlation around $414 \mathrm{~nm}$, its strength is quite poor $(R=0.9665, p<0.000)$ compared to a highly powerful negative correlation at around $590 \mathrm{~nm}(R=-0.9996, p<0.000)$, as obtained from the first approach.

Following the optimization of the method, it was then tested on real samples using the procedure described in the Experimental section and depicted in Figure 3. The water drop that was applied upon the paper sample diffused through the sample paper and reached the $\mathrm{pH}$ test strips changing their color, depending on $\mathrm{pH}$. Using the previously constructed calibration curve at $590 \mathrm{~nm}$, the $\mathrm{pH}$ of the paper was then calculated. The statistical results comprising of statistical descriptors and statistical tests results are shown in Table 1. One-way ANOVA reveals no statistical difference between the means of the three analytical methods, supporting the accuracy of the methods. However, the method proposed in this study is about three times more precise, as indicated by RSD\% and the Fischer test.

A.

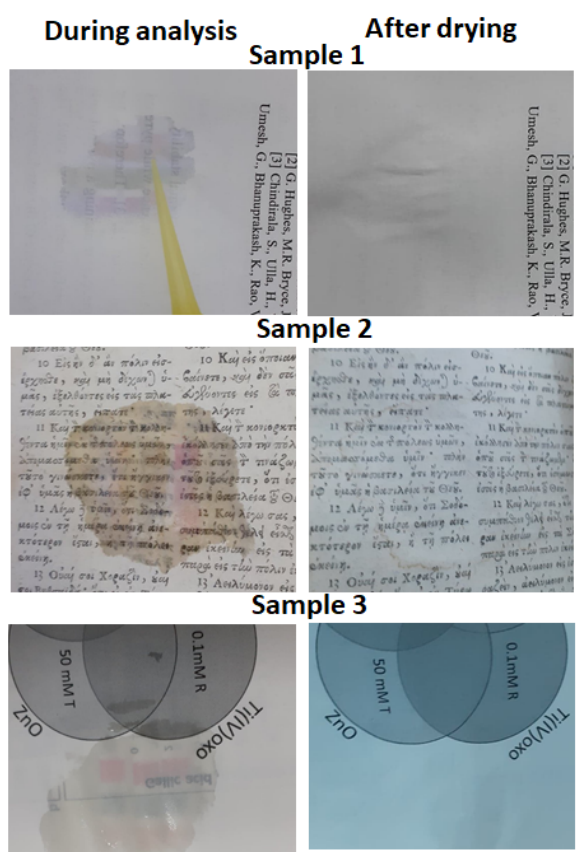

B.

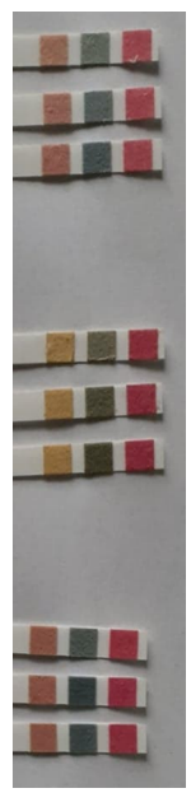

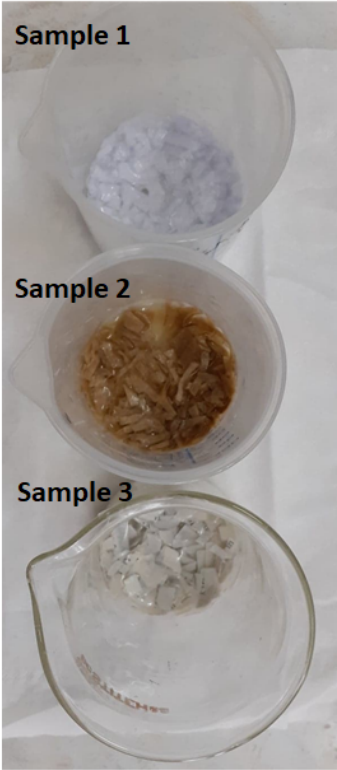

Figure 3. A. Image of the three tested real samples (described in the Experimental section) during analysis and after drying, and their corresponding $\mathrm{pH}$ indicator test strips, in triplicates. B. Image of the same three real paper samples used in destructive classical cold extraction sample for $\mathrm{pH}$ determination. 
It is clear that the proposed method is non-destructive as the analyzed paper zone remains intact after drying of the water, since this method requires a small amount of water. The electrochemical $\mathrm{pH}$ surface sensors that are commonly used nowadays for monitoring the $\mathrm{pH}$ of paper samples also requires a small amount of water. However, they are known to require a long time for equilibration and they also have poor precision and accuracy at short time, which is caused by the gradual diffusion of water away from the measurement region under the electrode. [11] In contrast with these methods, the classical cold extraction method is a destructive method that requires a certain amount of the paper sample to be cut away from the original sample in order to be extracted in water (Figure 3B), followed by $\mathrm{pH}$ meter reading. Despite expectance, this method is also not so precise, mostly due to the higher water dilution, and the influence of atmospheric carbon dioxide during extraction. In contrast with these classical methods, the procedure proposed in this work requires much shorter time of analysis ( 3 minutes water diffusion unto the indicator strips and 1 minute spectrum measurement). Moreover, by working at the optimum $590 \mathrm{~nm}$ wavelength, the linearity of the calibration curve is improved and the systematic acidic and alkaline methods that commonly accompany electrode-based methods are eliminated, thus explaining the high precision and accuracy of the method.

Table 1. Statistical results obtained for the three tested real samples

\begin{tabular}{|c|c|c|c|c|c|c|c|c|c|}
\hline & \multicolumn{3}{|c|}{ Sample 1} & \multicolumn{3}{|c|}{ Sample 2} & \multicolumn{3}{|c|}{ Sample 3} \\
\hline Method $^{\mathrm{a}}$ & M1 & M2 & M3 & M1 & M2 & M3 & M1 & M2 & M3 \\
\hline $\begin{array}{c}\text { Mean } \\
\text { pH }\end{array}$ & 8.43 & 8.46 & 8.47 & 6.02 & 5.96 & 5.97 & 7.78 & 7.93 & 7.99 \\
\hline RSD\% & 3.2 & 3.4 & 0.2 & 4.6 & 3.2 & 0.9 & 3.6 & 1.6 & 0.7 \\
\hline Min. & 8.00 & 8.01 & 8.44 & 5.75 & 5.72 & 5.89 & 7.43 & 7.80 & 7.95 \\
\hline Max. & 8.70 & 8.67 & 8.49 & 6.55 & 6.18 & 6.02 & 8.12 & 8.10 & 8.07 \\
\hline $\begin{array}{c}\mathrm{Cl} \\
(95 \%)^{\mathrm{b}}\end{array}$ & 0.33 & 0.30 & 0.03 & 0.17 & 0.24 & 0.07 & 0.23 & 0.15 & 0.08 \\
\hline $\begin{array}{c}p(F \\
\text { test) }\end{array}$ & - & 0.470 & 0.001 & - & 0.242 & 0.003 & - & 0.071 & 0.009 \\
\hline $\begin{array}{l}\text { ANOVA } \\
\text { analysis }\end{array}$ & \multicolumn{3}{|c|}{$\begin{array}{l}F=0.033 \\
p=0.967\end{array}$} & \multicolumn{3}{|c|}{$\begin{array}{l}F=0.194 \\
p=0.825\end{array}$} & \multicolumn{3}{|c|}{$\begin{array}{l}F=1.661 \\
p=0.225\end{array}$} \\
\hline
\end{tabular}

${ }^{\mathrm{a}} \mathrm{M} 1$ - classical paper cold extraction and $\mathrm{pH}$ meter, $\mathrm{M} 2-\mathrm{pH}$ glass electrode adapted for direct surface analysis, M3 - the method proposed in this study as described in the Experimental section. ${ }^{\mathrm{b}}$ Confidence interval at $95 \%$ probability $(n=5)$. ${ }^{\mathrm{C}}$ Fischer test for testing the variance compared to the M1 classical method. 
It is easily foreseen that the colored, non-bleeding $\mathrm{pH}$ indicator test strips that are obtained after water diffusion from the paper samples could be analyzed via other faster and simpler methods, such as image analysis. Therefore, this method is a good candidate for fast image analysis of $\mathrm{pH}$ test strips for paper artifacts and integrated in potential smartphone instrumentfree applications.

\section{CONCLUSIONS}

A non-destructive, simple, rapid, and highly precise method was developed and successfully applied for determination of $\mathrm{pH}$ of paper artifacts using univariate regression analysis and diffuse reflectance spectroscopy. The measurements were performed on commercial non-bleeding $\mathrm{pH}$ indicator test strips, using a small amount of ultrapure water that quickly dried after analysis. The method was similar in accuracy with classical cold extraction and $\mathrm{pH}$ meter-based methods but the precision was improved. The optimum wavelength was found to be $590 \mathrm{~nm}$ and this could be directly used for univariate calibration methods (in the $\mathrm{pH}$ range 4.00 -9.50) without the need of multivariate calibration methods. The proposed method could be extended in applicability for $\mathrm{pH}$ determination to other types of samples and does not require the mandatory use of standard $\mathrm{pH}$ solutions purchased from manufacturers. Calibration standards in the laboratory and the number of the standards used for calibration could be increased without affecting the duration of the analysis, due to the speed of obtaining the reflectance signal.

\section{EXPERIMENTAL SECTION}

\section{Reagents and materials}

Ultrapure water (18.2 $\mathrm{M} \Omega \mathrm{cm}, \mathrm{pH} 6.70-7.50)$ was used for all the solutions that were prepared in this study. A Britton-Robinson universal buffer solution was prepared in a final volume of $1 \mathrm{~L}$ by mixing boric acid, acetic acid and phosphoric acid, each at a final concentration of $50 \mathrm{mM}$. The solution $\mathrm{pH}$ was monitored using a three-point calibrated $\mathrm{pH}$ meter (Hanna Instruments $\mathrm{pH} 212$ microprocessor) with a two-decimal precision, and the desired $\mathrm{pH}$ values was reached using $10 \mathrm{M}$ sodium hydroxide solution that was added dropwise, while stirring continuously. Aliquots of $50 \mathrm{~mL}$ solution with $\mathrm{pH}$ values from 2.00 up to 10.00 -in this order-were drawn from the initial solution and deposited in falcon tubes, at an interval of $0.50 \mathrm{pH}$ units. 
Thus, seventeen $\mathrm{pH}$ standard solutions were prepared in the $2.00-10.00$ $\mathrm{pH}$ range - at an interval of $0.50 \mathrm{pH}$ units-that were used for calibration curves. Several ranges of non-bleeding $\mathrm{pH}$ indicator test strips, with different numbers of bands (Dosatest, VWR Chemicals) were used.

\section{Sample preparation and spectral measurement}

For the calibration curve, an aliquot of $15-50 \mu \mathrm{L} \mathrm{pH}$ standard solution was evenly spread on a $\mathrm{pH}$ indicator test strip and incubated for about two minutes. The excess of standard buffer solution was quickly removed with a clean pure cellulose tissue and the reflectance spectra were recorded in the desired region of the strips, before drying. A maximum of two adjacent bands from a strip could fit in the integrating sphere sample window. Three real samples originating from three books with different textured pages were chosen for the application of the optimized method - a book that used acid-free paper (Advanced Protocols in Oxidative Stress III, Humana Press, Springer 2015 as Sample 1), a New Testament in Greek from 1710 (H Kaívı $\Delta ı$ ıӨńkn as Sample 2) and a book that used regular modern paper (Book of abstracts 9th ICCSSEEC, Valahia University Press, Targoviste, 2011 as Sample 3). On a certain page of each book, $50 \mu \mathrm{L}$ of ultra-pure water were placed on the analysed region, using an automatic pipette. Prior to the water application, three $\mathrm{pH}$ indicator strips were laid just under the analysed paper zone, as shown in Figure 3A. After an incubation of about 3 minutes, it was checked whether the $\mathrm{pH}$ indicator strips were evenly moistened and then the reflectance spectra of the strips were measured. For the validation of the developed method, two other standard methods were used: method 1 (M1) - cold extraction method and method 2 (M2) - a pH electrode adapted for surface analysis. First method is a standard method, in which a modern calibrated pH-meter (Hanna Instruments $\mathrm{pH} 212$ microprocessor) is used to read the $\mathrm{pH}$ values of the paper cold extract, after equilibration. The cold extraction was adapted according to ISO 6588-1 [12], that requires $0.2 \mathrm{~g}$ of paper sample, cut into $5 \times 5 \mathrm{~mm}$ pieces and placed in a beaker containing $10 \mathrm{ml}$ ultrapure water at a temperature within the interval 20 to $25^{\circ} \mathrm{C}$ for one hour. The beaker was closed and agitated every 10 minutes. The M2 method involves the use of a glass electrode (SenTix 41 Plus connected to a InoLab WTW pH 720 meter) that reads $\mathrm{pH}$ directly from the paper that was cut, attached to the tip of the wet electrode, after 5 minutes incubation. The diffuse reflectance spectra in $350-750 \mathrm{~nm}$ spectral domain were recorded for every type of $\mathrm{pH}$ test strips, using a V-550 Jasco spectrophotometer that was equipped with an integrating sphere (Jasco ISV 469). The collection area is $1 \mathrm{~cm}^{2}$. The scan rate was set at medium, and the reflectance value was recorded every $1 \mathrm{~nm}$. All samples were measured at least in duplicates. White modern paper was used as $100 \%$ reflectance reference. The analytical steps form the proposed procedure are presented in Figure 4. 


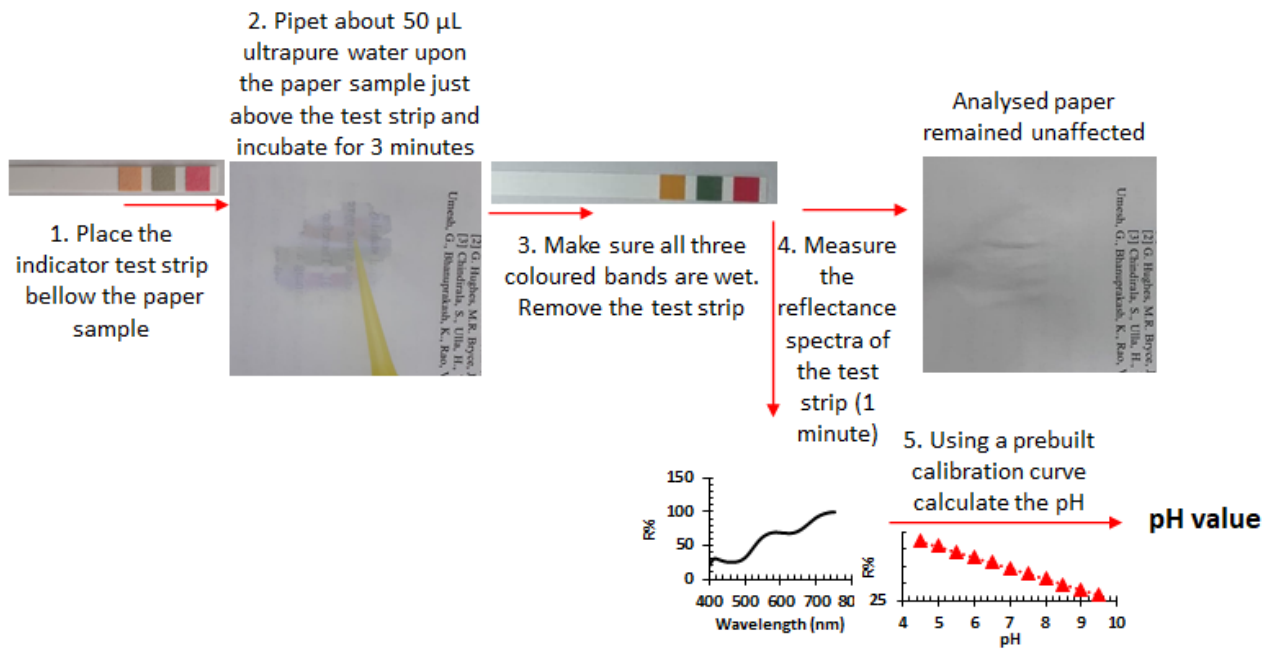

Figure 4. Key analytical steps required for the proposed method

\section{Statistical analysis}

The measured spectra of the calibration or testing samples were exported in txt format and then were min-max normalized in Excel using the formula:

$$
x_{i}^{\prime}=\frac{x_{i}-\min (x)}{\max (x)-\min (x)}
$$

The normalized spectra data matrix was further analyzed either using Excel or Statistica software (released by Statsoft, USA) for plotting or for regression analysis and Principal Component Analysis (PCA), that was applied on $350-750 \mathrm{~nm}$ normalized data matrix. One way ANOVA was used for testing the statistical difference between the three means for the three tested real samples with a significance level of 0.05 . Fischer $F$ test was applied for testing the statistical difference between the variances of method 2 and method 3 compared to the classical method 1, with a statistical significance level of 0.01 .

\section{ACKNOWLEDGMENTS}

This work was supported by UBB-TeMATIC Art P_40_374, project co-financed by FEDR through Competitiveness Operational Programme 2014-2020 


\section{REFERENCES}

1. M. Kostadinovska; Proc; 3rd Virtual Multidiscip. Conf., 2015, 3, 184-189.

2. I. Čabalová; F. Kačík; J. Gojný; B. Češek; M. Milichovský; O. Mikala, T. Tribulová; J. Durkovič; BioResources, 2017, 12, 2618-2634.

3. F. Coppola; N. Brown; F. Amicucci; M. Strlič; A. Modelli; Herit. Sci., 2020, 8, 1-10.

4. M. Strlič; J. Kolar; D. Kočar; T. Drnovesek; V.-S. Šelih; R. Susič; B. Pihlar; e-Preservation Sci., 2004, 1, 35-47.

5. R. Kumar; V. Kumar; V. Sharma; Spectrochim. Acta - Part A Mol. Biomol. Spectrosc., 2017, 170, 19-28.

6. V. Sharma; J. Kaur; R. Kumar; Aust. J. Forensic Sci., 2020, 52, 1-24.

7. R. Kumar; V. Kumar; V. Sharma; Appl. Spectrosc., 2015, 69, 714-720.

8. A. Zoleo; F. Vecchia; M. Brustolon; Appl. Magn. Reson., 2009, 35, 213-220.

9. A. Zoleo; L. Speri; M. Bronzato; Restaurator, 2015, 36, 269-282.

10. M. Strlič; I. K. Cigić; J. Kolar; G. De Bruin; B. Pihlar; Sensors, 2007, 7, 31363145.

11. A. Beneduci; F. Dalena; B. C. De Simone; I. Lania; G. De Filpo; M. C. Gallucci; G. Chidichimo; J. Phys. Chem. C, 2017, 121, 25180-25186.

12. https://www.iso.org/standard/77946.html, accessed on 06.05.2021. 